\title{
As Tarifas Alves Branco: entre o protecionismo e a preocupação
}

\section{fiscal}

Pedro Henrique Batista Barbosa*

Resumo: Na década de 1840, o vencimento dos tratados comerciais, resgatava antigos anseios da elite política imperial: desenvolver as manufaturas no país e aumentar as receitas do Estado. Após extensos debates, diversas medidas protecionistas foram lançadas, sendo as Tarifas Alves Branco as mais importantes. As tarifas buscaram atender mais a interesses fiscais do que a pretensões industrializantes.

Palavras-chave: Tarifas Alves Branco; Livre-cambismo; Protecionismo.

Abstract: In 1840s, the end of commercial treaties would satisfy longstanding wishes of the imperial political elite: to develop the national industries and to increase public revenues. After debate, several protectionist measures were taken, being the Alves Branco Tariffs the most important. The tariffs aimed at curbing the fiscal debit than to industrialize the country. Keywords: Alves Branco Tariffs; Free trade; Protectionism.

\section{Introdução}

O século XIX inaugurou-se sob o signo do progresso. O Antigo Regime ruíra, os pensamentos iluministas faziam-se cada vez mais presentes na mente de cidadãos e governantes, e o mercantilismo não mais se mostrava adequado à nova realidade industrial europeia. Avanços tecnológicos desde a Revolução Científica criaram a perspectiva de que a prosperidade estaria ligada a industrialização ${ }^{1}$, sendo a Inglaterra o exemplo de sucesso a ser seguido por muitas nações ainda submetidas ao jugo colonial, mas que enxergavam nesse processo industrial o complemento econômico necessário da aspiração à independência política.

No Brasil não foi diferente. Desde a sua elevação à categoria de Reino Unido ao de Portugal, a princípio, e a de Estado independente, a seguir, o país debatia-se, por um lado, entre os interesses agrícolas, cada vez mais preponderantes, e por outro, a vontade de

\footnotetext{
* Diplomata, formado em Direito pela PUC-Rio. Mestre em Diplomacia pelo Instituto Rio Branco

${ }^{1}$ Usar o termo industrialização não é adequado ao se referir ao século 19 . No presente trabalho, ele será por vezes usado como sinônimo de formação de fábricas e manufaturas.
} 
industrializar-se. ${ }^{2}$ Entretanto, em função dos condicionantes históricos, o debate restringiu-se, grosso modo, ao campo intelectual.

Em 1810, assinava o Príncipe Regente Dom João uma série de acordos com a GrãBretanha, de quem dependia o governante português para libertar Portugal do domínio napoleônico, em troca do apoio-sobretudo logístico-para a transmigração da corte portuguesa ao Brasil. Foram firmados os tratados de Aliança e Amizade e de Comércio e Navegação, que determinavam diversos privilégios aos produtos e cidadãos ingleses no Brasil, a ponto de o Conde de Palmela afirmar que "nunca um tratado foi tão espoliativo". Além do direito de extraterritorialidade, segundo o qual qualquer crime feito no Brasil por cidadão britânico seria julgado conforme as leis e juízes ingleses-Juiz Conservador da Nação Inglesa-, o representante português no Congresso de Viena insurgiu-se, sobretudo, contra a cláusula alfandegária, que inviabilizou a política fomentista implantada por Dom João na nova capital do Império Português.

Pelo novo tratado, os produtos ingleses pagariam nos portos brasileiros a tarifa alfandegária de $15 \%$, ao passo que os portugueses pagariam $16 \%$ e os restantes, $24 \%$. Estava selada a hegemonia britânica no país, que se valia da qualidade e do preço de seus produtos para controlar o comércio nacional. ${ }^{3}$

A despeito de forte oposição interna, seja de comerciantes nacionais prejudicados pelas tarifas preferenciais aos ingleses, seja da elite política e intelectual do país, contrária ao que considerava um atentado à soberania, o tratado foi renovado em 1827, sendo que novamente os condicionantes históricos pesaram na decisão brasileira. Recém-declarado independente, necessitava o Brasil do reconhecimento internacional, sobremodo da ex-metrópole Portugal, no qual Dom Pedro I empenhou-se pessoalmente. Todavia, foi preciso recorrer mais uma vez à ajuda inglesa, que, após a assinatura do tratado de Paz e Amizade Luso-Brasileiro em 1825, impôs uma convenção sobre o fim do tráfico negreiro em 1826 e a renovação do Tratado de Paz e Amizade, Comércio e Navegação Anglo-Brasileiro, válido por mais quinze anos a partir de 1827.

Em meados do século XIX, a elite política do Império brasileiro defrontou-se com a oportunidade de dar novos rumos à política externa do país. Em vista da proximidade da

\footnotetext{
${ }^{2}$ Cumpre destacar que preocupações industrialistas são encontradas já no século XVIII, a exemplo dos planos dos Inconfidentes Mineiros de fomentar o desenvolvimento manufatureiro em sua República.

${ }^{3}$ Historiadores como Roberto Simonsen e Caio Prado Júnior consideram essa convenção imposta a Dom João pela Inglaterra como tendo sido indiscutivelmente prejudicial ao estabelecimento de manufaturas no Brasil, posição à qual Celso Furtado se opõe.
} 
expiração dos tratados desiguais em $1844^{4}$, reacendeu-se a discussão entre os defensores do setor agrícola e os patronos da causa industrial, ressurgindo o debate sobre a questão do protecionismo alfandegário como mecanismo de fomento às manufaturas nacionais.

\section{Protecionismo e livre-cambismo}

O processo de fortalecimento do poder central, a partir de 1840, coincidente com a Maioridade e o fim do período regencial, somado ao arrefecimento das rebeliões provinciais, forneceria as condições políticas para que os governantes redirecionassem a política externa a partir de uma leitura mais ampla dos interesses nacionais ${ }^{5}$. Tinha o Estado condições de engajar sua estrutura completa na elaboração e na implementação da política externa. Esse processo subia do Conselho de Estado ao monarca e descia ao Parlamento, onde era acompanhado pela Câmara e pelo Senado, para chegar ao Gabinete, que o executava ${ }^{6}$. Não é sem motivo que a extinção progressiva do sistema de tratados permitiu a reflexão sobre a inserção da economia brasileira no sistema internacional.

Se as condições internas eram favoráveis à implementação de uma política externa mais independente da influência inglesa, o contexto internacional requeria certa habilidade. Vivenciava-se a expansão da Revolução Industrial no continente europeu e nos Estados Unidos, a construção de estradas de ferro e o aparecimento da navegação moderna. A concorrência internacional produzia conflitos comerciais e alfandegários, a busca de mercados, o colonialismo e o imperialismo. Nesse contexto, não era fácil ao Brasil manter a autonomia alfandegária e recorrer ao protecionismo em favor das manufaturas nacionais ${ }^{7}$.

Nessas circunstâncias, emerge, tanto no Parlamento e no Conselho de Estado quanto nos Ministérios da Fazenda e de Negócios Estrangeiros, debate sobre qual seria a política alfandegária mais apropriada para o Império.

O Ministério dos Negócios Estrangeiros posicionava-se claramente contrário aos tratados comerciais então vigentes. Nas palavras do Ministro Aureliano de Souza e Oliveira Coutinho:

\footnotetext{
${ }^{4}$ Em verdade, o prazo final dos tratados seria o ano de 1842, mas foi prorrogado até 1844 por pressão inglesa.

${ }^{5}$ FILHO, José Gilberto Scandiucci. Hegemonia britânica e o debate entre protecionismo e livre-cambismo no Império brasileiro (1843-1866). Revista Múltipla, Brasília, vol. 9, n. 13, dez. 2002, p. 63.

${ }^{6}$ CERVO, Amado Luiz; BUENO, Clodoaldo. História da política exterior do Brasil. 2. ed. Brasília: Editora Universidade de Brasília, 2002, p. 67.

${ }^{7}$ Ibid. p. 69.
} 
He só nessa época futura, quando hajão cessado as estipulações de todos os Tratados, ora existentes, onde em verdade não foram devidamente atendidos os interesses do Brazil. Com a reciprocidade, a que tem jus incontestável, que o Governo Imperial, se o julgar conveniente, attenderá aos diversos convites, que lhe tem sido feitos, para se encetarem novos Tratados de Commercio. ${ }^{8}$

Estava o Ministro não só preocupado com interesses comerciais e fiscais do país, mas também com a soberania nacional, que foi, por longo tempo, violada por diversas previsões contratuais, a exemplo do foro privilegiado aos cidadãos britânicos.

A legação de Sua Majestade Britannica protestou contra a cessação do Foro privilegiado da Nação Ingleza no Imperio (...) a existencia do Tratado que outorgou o privilegio para as causas dos Subditos Britannicos, julgou o Governo Imperial que era chegado o tempo fazer cessar esta anomalia no systema judiciario do Brazil. ${ }^{9}$

Das mesmas opiniões compartilhavam outros Ministros que ocuparam o cargo posteriormente, como Bento da Silva Lisboa:

Os maos effeitos dos tratados que o Brazil, alguns annos depois de sua emancipação política, celebrou com varias potencias pelos embates que de continuo nelles encontrarão os verdadeiros interesses do paíz, as questões e mesmo complicações que sobrevierão nas relações com varios governos, o futuro embaraçoso que nos legarão certos compromissos que ainda hoje subsistem, estos e outros motivos trouxerão a crença de que os tratados não são os melhores meios de estreitar os vinculos que ligão as nações entre si. ${ }^{10}$

O sucessor Ministro Paulino José Soares de Souza manteve o mesmo espírito contestador e buscou, em todas as suas negociações comerciais, igualdade de tratamento e reciprocidade. Opinando sobre projeto de convenção comercial apresentado em 1848 pela Inglaterra ao Brasil, opôs-se a qualquer acordo que não incluísse entre as suas disposições a cláusula de nação mais favorecida e a da não discriminação.

o governo do Brazil em suas relações commerciaes seguiria com as outras nações a política da mais perfeita igualdade de tratamento, emquanto os navios do Brazil e mercadorias nelles importadas fossem recebidas aos

\footnotetext{
${ }^{8}$ BRASIL. Ministério dos Negócios Estrangeiros. Relatório do anno de 1840 apresentado a Assembléa Geral Legislativa na sessão ordinária de 1841. Rio de Janeiro: Typographia Nacional, 1841. p. 10.

${ }^{9}$ Id. Relatório do anno de 1844 apresentado a Assembléa Geral Legislativa a 13 de janeiro de 1845 , na $1^{\text {a }}$ sessão

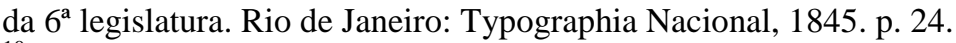

${ }^{10}$ Id. Relatório do anno de 1846 apresentado a Assembléa Geral Legislativa na $4^{a}$ sessão da $6^{a}$ legislatura. Rio de Janeiro: Typographia Imperial e Constitucional de J. Villeneuve e Comp., 1847. p. 23.
} 
portos daquellas nações, pelo que diz respeito aos direitos de navegação, de porto e de alfandega, como os seus proprios nacionaes. ${ }^{11}$

O Ministério de Negócios Estrangeiros teve apoio do Conselho de Estado, que reiterou a necessidade de reciprocidade nos tratados quando foi consultado, por exemplo, sobre a minuta de tratado oferecida ao Governo Imperial pelo Enviado Extraordinário e Ministro Plenipotenciário da Inglaterra, Henry Ellis, em 1844, e sobre a minuta do Tratado de Comércio e Navegação com o Zollverein, apresentada em 1845.

Três eram os principais defensores de medidas protecionistas no Conselho de Estado. Souza Franco, baseado, sobretudo, em razões fiscais e sociais-uma numerosa população desocupada representaria uma ameaça ao governo-, discursava em prol da indústria incipiente existente à época e opunha-se à redução de taxas sobre artigos manufaturados similares aos de produção nacional.

Não podendo aspirar a nos convertemos em nação manufatureira, pelo menos nesses anos próximos, não devemos contudo privar de emprego capitais que, nas cidades e nas vilas, não podem empregar-se na agricultura, e trabalho, braços e habilitações, que por igual motivo precisam ocupar-se em trabalhos industriais. ${ }^{12}$

Outro membro do Conselho, o Visconde de Itaboraí, preconizava o protecionismo por motivos econômicos. Julgava ser a produção manufatureira fenômeno imprescindível à prosperidade do país, por causa da maior elasticidade apresentada pela produção fabril que, diferentemente da agrícola, não estava sujeita a fenômenos climáticos.

A produção entre as nações manufatureiras tem elasticidade indefinida e quase ilimitada: produtos que se fabricavam há muitos anos em muitos dias e por alto preço, podem fabricar-se hoje em menos tempo e com muita mais economia de despesa. Os produtos da lavoura não são suscetíveis de semelhante progresso; estão sujeitos à lei inflexível das estações, não há invenção de maquinismos que faça o café, a cana produzir mais de uma vez por ano, e é por isso que não há nação exclusivamente agrícola, que possa crescer e prosperar, como as nações manufatureiras. ${ }^{13}$

\footnotetext{
${ }^{11}$ Id. Relatório do anno de 1849 apresentado a Assembléa Geral Legislativa na $1^{\text {a }}$ sessão da $8^{\text {a }}$ legislatura. Rio de Janeiro: Typographia Imperial e Constitucional de J. Villeneuve e Comp., 1850. p. 6.

${ }^{12}$ Id. Conselho de Estado. Consulta d'Estado Pleno. Rio de Janeiro, 1867. p. 41-42 apud LUZ, Nícia Vilela. A luta pela industrialização do Brasil (1808 a 1930). $1^{\text {a }}$ ed. São Paulo: Difusão Europeia do Livro, 1961. p. 28.

${ }^{13}$ Ibid. p. 29.
} 
Itaboraí foi Ministro da Fazenda de 1848 a 1853 - um recorde num período em que os gabinetes duravam em média pouco mais de um ano - e entre 1868 e 1870; foi Presidente do Conselho de Ministros por duas vezes. Em todos esses momentos, foi árduo defensor da indústria nascente brasileira. Segundo ele, uma economia especializada na exportação de matérias-primas ou gêneros alimentícios estaria vulnerável a mudanças súbitas no mercado internacional; "a experiência demonstra que a acumulação de riquezas é muito mais lenta nos países puramente agrícolas, do que nos manufatureiros ou comerciais”. Apregoava o apoio governamental no processo de diversificação da atividade produtiva: "nenhuma das nações conhecidas tem chegado a grande desenvolvimento industrial senão à sombra de leis protetoras". Argumentava ainda que só deve ser digna de proteção a indústria "que possa em prazo mais ou menos breve chegar a certo ponto de robustez, que a habilite a viver e crescer de seus próprios recursos, e dar benefícios superiores aos sacrifícios que custar" ${ }^{\text {,14 }}$

Honório Hermeto Carneiro Leão foi outra figura importante nos debates pró-tarifa no Conselho de Estado. Sobre a concessão de direitos diferenciais para determinados produtos em possível tratado comercial a ser assinado com o Zollverein, salientou:

(...) não se devem pedir tais direitos a favor do Brasil senão para o açúcar e café, e em troca se deverão conceder ao Zollverein direitos diferenciais sobre determinados tecidos de seda, linho, lã e algodão, que mais the convierem, à exceção dos tecidos de algodão mais grosseiros, porque podemos aspirar a promover sua fabricação no Brasil. ${ }^{15}$

Em debate sobre a conveniência de se revogarem as concessões feitas a algumas fábricas em diversas províncias do Império, isentas de pagar impostos pelas matérias-primas importadas empregadas em atividades industriais, o Conselheiro esclareceu que somente tarifas alfandegárias não seriam suficientes: "por não ser bastante para proteger a indústria a tarifa, que tendo atendido a alguns ramos dela não compreende todos os que podem aparecer de novo, e que não poderão ser atendidos. (CARNEIRO LEÃO, 1850)"16

No Parlamento brasileiro, o debate entre livre-cambismo e protecionismo remonta à década de 1830, quando o Senado, por unanimidade, não renovou o tratado comercial com a Áustria em 1835-1836. Os parlamentares dividiam-se em dois grupos. Bernardo Pereira de

${ }^{14}$ VERSIANI, Flávio Rabelo. As Longas Raízes do Protecionismo: 1930 e as Relações entre Indústria e Governo. Revista EconomiA, Brasília, v. 13, n. 3b, dez. 2012, p. 876.

${ }^{15}$ CONSELHO DE ESTADO PLENO. Atas do Conselho de Estado Pleno: Terceiro Conselho de Estado, 18421850. Disponível em: <http://www.senado.gov.br/publicacoes/anais/pdf/ACE/ATAS3Terceiro_Conselho_de_Estado_1842-1850.pdf >.p. 59.

${ }^{16}$ Ibid. p. 76. 
Vasconcelos reivindicava a entrada do Brasil na era da "revolução industrial", termo cunhado à época, por intermédio de uma política protecionista radical, ampla e sustentada. Acompanhavam-no Vergueiro, Alves Branco, Carneiro Leão, Montezuma, Abrantes e as maiorias na Câmara, no Conselho de Estado e no Senado, entre 1843 e 1847. Os livrecambistas eram liderados por Francisco de Paula Souza e Melo e Holanda Cavalcanti de Albuquerque e defendiam a economia agrícola ${ }^{17}$.

Os liberais associavam o livre comércio à ideia de modernidade. Argumentavam que a proteção à indústria poderia comprometer a vocação agrícola do país, posição que beneficiava as classes dominantes da estrutura social, seja a fundiária, seja a comercial. Exigiam a imposição de tarifas sobre a importação de matérias-primas, como forma de estimular a produção dos recursos naturais nacionais.

A influência liberal na política brasileira remonta à figura de José da Silva Lisboa, conselheiro do Príncipe Dom João após a chegada da corte portuguesa ao Rio de Janeiro. Influenciado sobretudo pelos fisiocratas franceses e levando em consideração a primazia dos interesses agrícolas no país, o Visconde de Cairu era do parecer de que o auxílio estatal às indústrias com o fito de diminuir as importações refletiria sobre a exportação de produtos brasileiros, causando danos à renda nacional e ao Estado brasileiro. ${ }^{18}$

Décadas depois do Visconde, Holanda Cavalcanti apregoava o liberalismo e citava, com recorrência, o exemplo holandês e inglês, cujo desenvolvimento industrial teria sido ocasionado justamente pelas baixas tarifas. Quando perguntado sobre a necessidade de proteger a manufatura nascente brasileira, reagia com ironia: "Qual é a indústria que nós temos que precise de afastar a concorrência estrangeira? Não vejo. (CAVALCANTI, 1843:655)"19

Qual é a indústria a que queremos dar a nossa proteção? (...) A fonte principal de nossas riquezas é a indústria agrícola; com uma grande importação de gêneros fabricados no estrangeiro nós protegemos a nossa indústria agrícola; quanto mais gêneros de indústria fabril forem impor no Rio de Janeiro, tanto mais será protegida nossa indústria agrícola, porque os nossos gêneros serão consumidos ou trocados por estes importadores da indústria fabril. (...) e convirá proteger atualmente a indústria fabril com detrimento da indústria agrícola? (...) Nunca sacrificaria os interesses da nossa indústria agrícola a nenhum progresso da fabril, porque estou persuadido que a nossa posição geográfica, as circunstâncias peculiares de nosso país, favorecem mais a agricultura do que nenhuma outra indústria. ${ }^{20}$

${ }^{17}$ CERVO, Amado Luiz; BUENO, Clodoaldo. Op. Cit., p. 73.

${ }^{18}$ Silva Lisboa e suas ideias liberais eram muito criticadas por Hipólito da Costa no jornal Correio Braziliense.

${ }^{19}$ BRASIL. Senado Federal. Sessão de 28 de setembro de 1843. Anais do Senado. Brasília, v.8, p. 655.

${ }^{20}$ Id. Sessão de 29 de setembro de 1843. Anais do Senado. Brasília, v.8, p. 686-687. 
Da parte dos protecionistas, na década de 1840, a voz mais forte no Senado em defesa do protecionismo foi a de Bernardo Pereira de Vasconcelos, que enxergava nas tarifas o melhor meio de impulsionar a industrialização brasileira: "quero promover as artes com meu voto, quero chamá-las ao país, naturalizá-las nele; julgo que um dos meios mais adequados para se conseguir isto é aumentar os direitos de importação." 21

\begin{abstract}
Autorizar o governo a fixar os direitos, principalmente em certos gêneros (eu encaro a questão industrialmente), poderá auxiliar qualquer ramo da indústria que prometa medrar, prosperar no Brasil. Se ele não for autorizado a fazer ensaios deste modo, o que há de necessariamente acontecer é que as coisas marcharão como até aqui: não poderá prosperar ramo algum da indústria, por isso que não é possível consegui-lo sem grande proteção. ${ }^{22}$

Nós que estamos como que ainda no berço a respeito de matérias industriais; nós que temos de sofrer uma revolução industrial imensa; nós que devemos olhar para as alfândegas como o único recurso que resta para salvar o país. ${ }^{23}$
\end{abstract}

É interessante notar que os argumentos protecionistas encontraram respaldo em outros órgãos estatais. No Ministério da Fazenda, por exemplo, o Ministro Joaquim José Rodrigues asseverou:

(...) a experiencia demonstra que a accumulação das riquezas he muito mais lenta nos Paizes puramente agricolas, do que nos manufactureiros $e$ commerciaes. Cumpre pois excitar novas forças productivas, procurando conseguir que parte da nossa população se applique em fabricar alguns dos artigos de consumo que recebemos dos estrangeiros. (...) Nenhuma das Nações conhecidas tem chegado a grande desenvolvimento industrial senão à sombra de leis protetoras. ${ }^{24}$

Os anos compreendidos entre 1843 e 1855 podem ser analisados como o auge do pensamento protecionista no Parlamento e no Conselho de Estado. Para tanto, muito contribuiu a influência do Visconde de Itaboraí na política econômica imperial. Os Conselheiros favoreciam o intervencionismo governamental na economia, o estímulo à indústria local e uma política tarifária protecionista.

Diversas medidas de cunho protecionista foram debatidas e aprovadas entre $1843 \mathrm{e}$ 1855. Em 1843, é aprovado dispositivo mediante o qual o Executivo poderia gravar as mercadorias importadas no intervalo entre $2 \%$ e $60 \%$.

${ }^{21}$ Id. Sessão de 25 de abril de 1843. Anais do Senado. Brasília, v.4, p. 338.

${ }^{22}$ Id. Sessão de 27 de setembro de 1843. Anais do Senado. Brasília, v.8, p. 644.

${ }^{23}$ Id. Sessão de 28 de setembro de 1843 . Anais do Senado. Brasília, v.8, p. 655.

${ }^{24}$ BRASIL. Ministério da Fazenda. Proposta e relatório do anno de 1849 apresentados a Assembléa Geral Legislativa na $1^{\mathrm{a}}$ sessão da $8^{\mathrm{a}}$ legislatura. Rio de Janeiro: Typographia Nacional, 1850. p. 32. 
A Tarifa Alves Branco também é conhecida como avanço dos protecionistas. A Tarifa foi lançada pelo Decreto $\mathrm{n}^{\circ} 376$, de 12 de agosto de 1844, que tributava em $30 \%$ grande parte dos artigos estrangeiros. Ecoando argumentos em prol da reciprocidade em tratados, os artigos 20 e 21 autorizam impor sobretaxas aos produtos de países que taxem mercadorias brasileiras em seus portos.

Art. 20. O Governo fica autorisado a impor nos generos de qualquer Nação estrangeira, que em seus portos carregar as mercadorias brasileiras de maiores direitos, do que as de igual natureza de outra qualquer Nação, hum direito differencial, que contrabalance o máo effeito da desigualdade, ou que a obrigue a abolil-a, mas esse direito cessará logo que cesse a mesma desigualdade.

Art. 21. Hum igual direito differencial será arrecadado nas Alfandegas do Brasil dos generos daquellas Nações que cobrarem sobre quaesquer generos importados em seus portos em Navios brasileiros, maiores direitos de consumo do que sobre os importados em seus proprios Navios, procedendo-se ácerca delles da mesma maneira que sobre os do Artigo antecedente. ${ }^{25}$

Some-se ainda o Decreto $\mathrm{n}^{\mathrm{o}} 386$, de 08 de agosto de 1846, que concedeu vários privilégios à indústria nacional, entre eles a isenção, por dez anos, dos direitos de entrada sobre máquinas, ou peças de máquinas, importados para uso nas fábricas de tecidos de algodão.

Em 1847, emergiu no Senado a questão da proteção à marinha mercante nacional, o que faria parte, nas palavras do Visconde de Abrantes, de um projeto maior de defesa da indústria nacional. Nesse sentido, foram aprovados diversos decretos, que estabeleceram a aplicação de uma taxa adicional em um terço da ancoragem prevista no decreto de 1844 , no caso das embarcações das nações que carregassem sobre os navios brasileiros ancoragem (ou quaisquer outros direitos de porto) maior do que pagam os seus próprios navios. Segundo o então Ministro de Negócios Estrangeiros Limpo de Abreu:

As nossas relações commerciaes tomarão uma face toda nova depois do decreto de $1^{\circ}$ de outubro de 1847, que estabeleceu direitos differenciaes em conformidade do decreto de 20 de julho de 1844, o qual determinou que as embarcações das nações que carregassem sobre os navios brazileiros ancoragem ou quaesquer outros direitos de porto maiores do que pagão seus proprios navios, ficarião sujeitas nos nossos portos a mais um terço da ancoragem ali estabelecida, e do art. 21 do decreto de 12 de agosto de 1844, que determinou que um direito differencial fosse tambem arrecadado

${ }^{25}$ Id. Decreto n. 376, 12 de agosto de 1844. Manda executar o Regulamento e Tarifa para as Alfandegas do Imperio. Lex: Colecção das Leis do Imperio do Brasil, Rio de Janeiro, tomo $7^{\circ}$, parte $2^{\text {a }}$, seção $26^{\text {a }}, 1844$. 
nas alfandegas do império sobre as mercadorias importadas em navios daquellas nações que cobrassem, sobre quaesquer generos importados em seus portos em navios brazileiros, maiores direitos de consumo do que se fossem importados em seus proprios navios.

Estes dous decretos tinhão por fim proteger a marinha mercante do imperio. $^{26}$

Dirigindo-se às nações estrangeiras para explicar os motivos que ensejaram a publicação do referido decreto, acrescentou:

Senhor - Entre os meios de que todas as nações maritimas tem lançado mão para protegerem sua marinha mercante, figura em primeiro lugar a imposição de direitos differenciaes sobre os navios daquellas nações que o impozerem nos das outras para contrabalançar o mao effeito de tal medida; assim applicados, os direitos differenciaes são justos e prestão eficaz proteção, fazendo remover uma desigualdade intolerável. ${ }^{27}$

Em análise das relações comerciais bilaterais entre o Brasil e vários países, Limpo de Abreu ressaltou a importância de se obter reciprocidade na assinatura de tratados comerciais, que deveriam garantir a igualdade de tratamento.

A reciprocidade que aí se exige não consiste em que cada nação cobre sobre os nossos navios o mesmo que nós cobramos sobre os dela, mas sim que cobre sobre os nossos o mesmo que sobre os seus, por isso nós cobramos sobre os seus os mesmos que sobre os nossos. ${ }^{28}$

É salutar que a medida brasileira teve repercussão internacional, ao ponto de algumas nações mostrarem-se interessadas em entabular negociações com o Brasil com vistas a assinar acordos comerciais consubstanciados na reciprocidade.

Exm. Sr. - O governo da raínha tomou em consideração o decreto do governo imperial com a data de $1^{\circ}$ de outubro de 1847, pelo qual se impõe direitos differenciaes sobre as embarcações estrangeiras; e havendo dado a devida attenção ao teor do dito decreto, e aos termos em que é concebido o seu art. $3^{\circ}$, o qual exceptua do pagamento de direitos differenciaes os navios daquellas nações que por ajustes ou por convenções se comprometerem por um tempo determinado a receber os navios brazileiros nos seus portos no mesmo pé de igualdade perfeita que os seus proprios navios, ordenou-me

26 Id. Ministério dos Negócios Estrangeiros. Relatório do anno de 1847 apresentado a Assembléa Geral Legislativa na $1^{\circ}$ sessão da $7^{\mathrm{a}}$ legislatura. Rio de Janeiro: Typographia Imperial e Constitucional de J. Villeneuve e Comp., 1850. p. 10.

27 Id. Ministério dos Negócios Estrangeiros. Relatório do anno de 1847 apresentado a Assembléa Geral Legislativa na $1^{\mathrm{o}}$ sessão da $7^{\mathrm{a}}$ legislatura. Rio de Janeiro: Typographia Imperial e Constitucional de J. Villeneuve e Comp., 1850. p. 36.

${ }^{28}$ Ibid. p. 6. 
que declarasse a V. Ex. estar elle prompto a entrar em um ajuste com o governo imperial com aquelle fim. (...) James Hudson. ${ }^{29}$

Outra medida de cunho protecionista foi a lei orçamentária de 1848, que aumentou impostos em $80 \%$ para importações de calçados, roupas-feitas e peças de marcenaria, medida que causou a oposição de vários países.

(...) o Sr. Felippe Eugenio Guillemot, encarregado de negocios da Republica Franceza, referindo-se ao art. $9^{\circ}, \S 1^{\circ}$ da lei do orçamento de 28 de outubro desse anno, que mandou pôr logo em execução imposto de 80 p.c. lançado sobre a importação do calçado, roupa-feita e obras de marcenaria, fez sobre a cobrança immediata desse imposto e sobre seus effeitos varias considerações com o intuito de desviar do commercio de seu paiz os prejuizos que entende resultão das disposições daquella lei. ${ }^{30}$

Para além das tarifas e isenções, outros tipos de auxílios foram concedidos ao longo dos anos de 1840 a determinadas indústrias, sob a forma de empréstimos ou de concessão de loterias (forma muito comum de auxílio governamental à época).

A prevalência da corrente protecionista no Parlamento e no Conselho de Estado entre 1843 e 1855 não impediu que medidas visando favorecer industrias nacionais fossem adotadas antes de 1844, ou melhor, no período de vigência dos tratados celebrados em 1827 com a Inglaterra e outros países e que limitavam os direitos alfandegários à taxa relativamente baixa de 15\%. Em 28 de abril de 1809, o alvará de D. João que abriu os portos brasileiros a todas as nações amigas também ordenava a concessão de subsídios, a fundo perdido, para as manufaturas mais necessitadas, "particularmente [as] de lã, seda, algodão e fábricas de ferro e aço", acrescentando também, como estímulo a "inventores e introdutores de uma nova máquina", a garantia de sua exploração exclusiva por quatorze anos. ${ }^{31}$ Essa isenção foi mantida, após a Independência. ${ }^{32}$

O Regulamento das Alfândegas, de 1832, institucionalizou a isenção de direitos para "matérias primas para uso das fábricas nacionais", estendendo o benefício para máquinas utilizadas "em qualquer gênero de indústria". O Regulamento foi modificado em 1836; a

\footnotetext{
${ }^{29}$ Id. Relatório do anno de 1849 apresentado a Assembléa Geral Legislativa na $1^{\text {a }}$ sessão da $8^{\text {a }}$ legislatura. Rio de Janeiro: Typographia Imperial e Constitucional de J. Villeneuve e Comp., 1850. p. S1-28.

${ }^{30}$ Ibid. p. 123.

31 VERSIANI, Flávio Rabelo. As Longas Raízes do Protecionismo: 1930 e as Relações entre Indústria e Governo. Revista EconomiA, Brasília, v. 13, n. 3b, dez. 2012, p. 874.

${ }^{32}$ Mas D. João não deixou de acrescentar no Alvará uma profissão de fé liberal, sugerindo que a proteção seria temporária: "[com o tempo], a grandeza do mercado, e os efeitos da liberdade do comércio que tenho mandado estabelecer, hão de compensar com vantagem algum prejuízo ou diminuição que ao princípio possam sofrer alguns ramos de manufaturas". Ibidem.
} 
isenção foi mantida, desde que seja concedida autorização prévia do Tribunal do Tesouro, que fixaria a quantidade anual permitida de importação dos insumos, conforme o consumo previsto da fábrica solicitante. A entrada livre de máquinas ficou sujeita à decisão de uma comissão a ser criada em cada alfândega, que decidiria se a máquina importada poderia ou não ser fabricada no Brasil. ${ }^{33}$ Após o fim da vigência dos tratados desiguais, o Conselho de Estado decidiu, em 1857, pela revogação da isenção, com base no entendimento de que a tarifa não dava proteção suficiente à indústria nacional.

Em que pese o relativo predomínio do pensamento protecionista no Conselho de Estado e Parlamento, as tarifas alfandegárias sofreram diversas reformas a partir de meados do século XIX, coincidindo com a evolução do pensamento liberal na sociedade brasileira. É interessante notar que o avanço das ideias liberais no País não decorreu da pressão do capitalismo internacional. Não há evidências de pressões externas sobre as elites políticas do Império. Tal ausência sugere que as medidas foram decisão autônoma dos brasileiros, com base no liberalismo interno e, sobretudo no peso das estruturas sociais.

Se, a principio, foram os interesses britânicos o grande obstáculo ao estabelecimento de um protecionismo alfandegário, a partir dos meados do século XIX os seus maiores adversários foram, dentro do próprio país, as hostes liberais cujas doutrinas eram tão convenientes aos interesses da lavoura monocultora que, juntamente com a organização comercial que apoiava, dirigiam, então, os destinos do Império. ${ }^{34}$

Generalizações de que o governo, dominado pela atividade agroexportadora, agia sempre de acordo com os interesses dos grandes proprietários rurais são contraproducentes. As evidências aqui discutidas demonstraram que diversas medidas foram tomadas tendo em mente a proteção da indústria nacional. $\mathrm{O}$ confronto entre as correntes do pensamento protecionista e liberal manteve-se vivo durante todo o Segundo Reinado e era exacerbado quando se tratava de reformar a política alfandegária. No período de 1844 e 1889, não houve continuidade dessa política, mas, em realidade, oscilações bruscas que mais prejudicavam a expansão industrial. A tarifa de 1844 foi reformada, sucessivamente, a partir de $1857^{35}$, obstruindo, em longo prazo, quaisquer efeitos protetores da política de comércio exterior. ${ }^{36}$

\footnotetext{
${ }^{33}$ Ibidem.

${ }^{34}$ LUZ, Nícia Vilela. A luta pela industrialização do Brasil (1808 a 1930). $1^{\text {a }}$ ed. São Paulo: Difusão Europeia do Livro, 1961. p. 45.

${ }^{35}$ Valem citar a Reforma de Silva Ferraz de 1860 e a Tarifa Belisário de 1887, que possuíam viés mais liberal e buscavam atender mais os interesses do Fisco.

${ }^{36}$ CERVO, Amado Luiz; BUENO, Clodoaldo. Op. Cit., p. 77.
} 


\section{As condições do capitalismo e da industrialização brasileira}

Pelo alvará de $1^{\mathrm{o}}$ de abril de $1808^{37}$ e de 28 de abril de $1809^{38}$, revogava o Príncipe Regente Dom João as amarras do sistema colonial no Brasil e pretendia, sob a égide do liberalismo, introduzir a era industrial, com o fito de multiplicar a riqueza nacional, promover o desenvolvimento demográfico e dar trabalho a certo elemento da população que não se acomodava à estrutura socioeconômica vigente, que se definia, essencialmente, pelo regime escravocrata. $^{39}$

Estava inaugurado o debate sobre a formação de manufaturas no país, que, nas décadas seguintes, causou acaloradas discussões no seio da elite imperial. No entanto, tão importante quanto entender os argumentos desse debate é estudar o real estágio do capitalismo no país e as verdadeiras possibilidades de industrialização do Brasil em meados do século XIX.

Muito se atribuiu à falta de proteção tarifária e de incentivos governamentais o bloqueio da industrialização brasileira. Esse argumento, contudo, trata-se de um equívoco que cumpre afastar. Não se pode dizer que houve falta de proteção sobretudo depois de 1844 . Nem é lícito considerar reduzido seu nível, pois, como bem lembrou Celso Furtado, a primeira tarifa norte-americana era de $5 \%$ ad valorem para os tecidos de algodão, e a média, de 8,5 \%, alcançando-se 17,5 \% somente em 1810, quando a indústria têxtil já estava consolidada. ${ }^{40} \mathrm{O}$ verdadeiro problema está em explicar por que o nível de proteção, que jamais foi baixo, revelou-se insuficiente. Alguns estudiosos, normalmente economistas, arriscam-se a rejeitar a viabilidade de industrialização do Brasil ${ }^{41}$.

\footnotetext{
37 "Desejando promover e adiantar a riqueza nacional, e sendo um dos mananciaes della as manufacturas e a industria que multiplicam e melhoram e dão mais valor aos generos e productos da agricultura e das artes e augmentam a população dando que fazer a muitos braços e fornecendo meios de subsistencia a muitos dos meus vassallos, que por falta delles se entregariam aos vicios da ociosidade: e convindo remover todos os obstaculos que podem inutilisar e frustrar tão vantajosos proveitos.” BRASIL. Alvará de $1^{\circ}$ de abril de 1808. Permitte o livre estabelecimento de fabricas e manufacturas no Estado do Brazil. Lex: Colecção das Leis do Brazil de 1808. Rio de Janeiro: Imprensa Nacional, 1891. p. 10.

${ }^{38}$ Esse alvará representou mais um esforço para favorecer a introdução de fábricas no Brasil e determinou a isenção de direitos aduaneiros às matérias-primas necessárias às fabricas nacionais e de imposto de exportação para os produtos manufaturados brasileiros, utilização dos artigos nacionais no fardamento das tropas reais e a concessão de privilégios exclusivos.

${ }^{39}$ LUZ, Nícia Vilela. A luta pela industrialização do Brasil (1808 a 1930). $1^{\text {a }}$ ed. São Paulo: Difusão Europeia do Livro, 1961. p. 14.

${ }^{40}$ DE MELLO, João Manuel Cardoso. O capitalismo tardio: contribuição à revisão crítica da formação e do desenvolvimento da economia brasileira. $9^{\mathrm{a}}$ ed. São Paulo: Brasiliense, 1998. p. 74.

${ }^{41}$ Citem-se Celso Furtado, Nícia Vilela Luz, entre outros.
} 
É possível que a chave do problema possa ser encontrada no fato de o Brasil estar submetido a uma estrutura político-social de tipo Antigo Regime, com seus interesses mercantis solidamente estabelecidos. As condições existentes mostravam-se cada vez mais contrárias ao crescimento das manufaturas, uma vez que prevalecia, dominante, o agrarismo, que representava os mais fortes interesses do país e vinha a confirmar a crença no destino eminentemente agrícola do País.

O período entre 1810 e 1850 marcou os momentos de constituição, consolidação e generalização do consumo de café nos mercados centrais. Produzindo muito e barato, o Brasil venceu a concorrência de Ceilão e Java e tornou-se o primeiro produtor mundial. O café alçou-se a primeiro produto de exportação brasileira e sul-americana, e o país expandiu sua produção, entre 1820 e 1850, em cerca de seis vezes. Nesse momento, a economia mercantilescravista cafeeira assumiu seus traços definitivos, herdeiros do período colonial: grande empresa produzindo em larga escala e em grandes propriedades para exportação, apoiada no trabalho escravo, articulada a um sistema comercial-financeiro, controlados, uma e outro, nacionalmente. ${ }^{42}$ Trata-se da economia de plantation.

Em função do triunfo do pensamento escravista no Brasil, seria possível conciliá-lo com a constituição de uma indústria nacional baseada no trabalho escravo? Não é difícil entender que os custos da indústria escravista deveriam ser marcadamente superiores aos da indústria capitalista, calcada no trabalho assalariado.

O progresso técnico, que é próprio do capitalismo, está praticamente excluído da indústria escravista. Dentro dos quadros de uma economia mercantil-escravista, não é possível tanto uma maior divisão do trabalho como a especialização do escravo, porque era próprio de sua condição que se mantivesse res. Seria, pois, irracional ao empresário elevar seu grau de mecanização, visto que estaria, na verdade, "sucateando" parte do "equipamento" representado pelo mancípio antes que se esgote sua vida útil. ${ }^{43}$ Em contrapartida, a produtividade do trabalhador assalariado é muito maior do que a do escravo, mesmo considerando técnicas, utilização da capacidade produtiva e preços idênticos.

Outro ponto que dificultava a industrialização capitalista brasileira era que tanto o mercado consumidor como o de trabalho estavam vazios. A ausência de mercado consumidor decorre, obviamente, do fato de que parcela significativa da população era considerada coisa, mercadoria. Sem acesso ao mercado de trabalho livre e sem remuneração pelo seu labor, os

\footnotetext{
${ }^{42}$ Ibid. p. 57-58.

${ }^{43}$ Ibid. p 75.
} 
escravos não podiam consumir. A renda nacional era extremamente concentrada nas mãos dos comerciantes, dos financistas e dos cafeicultores, detentores dos meios de produção.

Embora houvesse homens livres e pobres em quantidade abundante, esses não estavam aptos a serem submetidos ao capital, como força de trabalho passível de se transformar em mercadoria. A abundância de terras representava um entrave à emergência da produção capitalista. João Cardoso de Mello esclarece melhor esse fenômeno:

Quando se expandia a economia mercantil-escravista, aos homens livres e pobres era dado ceder terreno, deslocando-se para o interior, ou, então, se fixar em faixas inaproveitadas, por uma ou outra razão, para a produção mercantil e escravista. Quando chegava a crise, em nada se afetava a situação dos homens livres e pobres que, porque dela não dependessem, continuavam pobres e livres, mas, ainda, produtores da própria subsistência. ${ }^{44}$

Em resumo, não havendo condições para a transformação da força de trabalho em mercadoria, pré-requisito indispensável, estaria bloqueada a industrialização capitalista. No entanto, não há de se pensar que somente isso seria suficiente.

Outros fatores concorreram para impedir o avanço industrial brasileiro. Teria que ser enfrentada a barreira representada pelos custos de transporte e pelas desvalorizações cambiais, que aumentavam o problema da capacidade de importar, dada a inexistência de uma indústria de bens de produção, ainda que manufatureira. Criavam grandes empecilhos as carências de capitais - os existentes aplicando-se preferencialmente em outros tipos de atividade econômica - de mão de obra capacitada, de máquinas, de espírito empresarial e de vontade de inovar. Mais recentemente, passou-se a destacar também a falta de segurança pública e a instabilidade política.

Diante do predomínio de um tipo capitalista de organização agrícola e escravista, o modelo produtivo brasileiro à época afastava-se do capitalismo moderno, calcado no trabalho assalariado e no contínuo aprimoramento tecnológico. O máximo que se poderia falar seria o que João Cardoso de Mello cunhou de "capitalismo de plantation". ${ }^{4}$

Em vista das dificuldades resultantes das condições econômicas do Brasil, eram insuficientes e incapazes de dar à indústria nacional um vigoroso impulso as tarifas aduaneiras estabelecidas naquele momento. É digno de nota que o incipiente avanço fabril que o Brasil teve em alguns setores, a exemplo da construção naval, siderurgia e têxtil, esteve

${ }^{44}$ DE MELLO, João Manuel Cardoso. Op. cit., p. 78.

${ }^{45}$ Ibid. p. 33. 
intrinsecamente vinculados ao papel preponderante desempenhado pelo Estado na economia da época.

\section{As Tarifas Alves Branco: uma opção majoritariamente fiscal}

A despeito de todo o debate apresentado entre livre-cambistas e protecionistas e acerca das reais possibilidades de industrialização do Brasil na segunda metade do século XIX, as Tarifas Alves Branco foram promulgadas oficialmente com duplo objetivo, oferecer uma proteção aduaneira à indústria brasileira e aumentar as receitas do Império, como explicitou o Ministro Paulino José Soares de Souza:

Sobre lei que aumenta impostos de importação: "Vós resolvereis, senhores, sobre o merecimento economico da medida adoptada por aquella lei, e se seus effeitos correspondem aos fins que teve em vista—augmento de renda e protecção à indústria do paíz. ",46

No entanto, a historiografia brasileira diverge sobre os reais motivos que ensejaram a publicação das referidas tarifas, constituindo basicamente duas correntes. De um lado, estão os historiadores minoritários que defendem o caráter essencialmente industrialista da medida. Do outro lado, figuram aqueles que a consideram como uma solução ao problema fiscal do Império.

Amado Luiz Cervo é o maior expoente da tese que as Tarifas Alves Branco representaram a vitória da facção industrialista no governo imperial. Segundo o autor, quando se extinguiu o sistema de tratados em 1844, surgiram condições para se elaborar novo projeto de política externa, não mais moldada para servir exclusivamente aos interesses da oligarquia fundiária, mas consubstanciada em percepções mais complexas do interesse nacional. Essa nova política externa abrangeria quatro propostas fundamentais: preservar a autonomia alfandegária, resistir a pressões externas contrárias a essa política econômica autônoma, estabelecer a reciprocidade real nas relações com o exterior e lançar as bases da indústria nacional por meio do protecionismo.

O projeto de 1844 seria uma proposta do Estado, que se colocava à frente da nação, ainda atrelada a estruturas arcaicas, e supria a carência de espírito empresarial na sociedade.

\footnotetext{
${ }^{46}$ BRASIL. Ministério dos Negócios Estrangeiros. Relatório do anno de 1849 apresentado a Assembléa Geral Legislativa na $1^{\mathrm{a}}$ sessão da $8^{\mathrm{a}}$ legislatura. Rio de Janeiro: Typographia Imperial e Constitucional de J. Villeneuve e Comp., 1850. p. 12.
} 
Por meio da tarifa protecionista, o Estado reafirmava sua autonomia, tanto em relação aos interesses internos da classe fundiária quanto aos interesses externos do capitalismo industrial.

Grande parte da historiografia sobre o tema discorda dessa opinião. Sérgio Buarque de Holanda não enxerga as tarifas como uma medida eminentemente protecionista do Estado, até porque elas não atingiram o fim a que se propuseram: industrializar o país. Segundo o autor, a taxa de $30 \%$ era insuficiente para uma proteção eficaz, e o próprio Alves Branco teria reconhecido que a nova pauta era pouco satisfatória do ponto de vista protecionista, dando a entender que, em função das exigências do fisco, fora impossível ao governo estabelecer tarifas que realmente amparassem as manufaturas brasileiras. ${ }^{47}$

Repousando o sistema tributário brasileiro na renda alfandegária, que, na década de 1850 , representava $62 \%$ da arrecadação total do país, exigiam, portanto, as necessidades orçamentárias uma tarifa com fins fiscais. No impasse entre atender os interesses do fisco e da elite industrial, as Tarifas Alves Branco foram incapazes de satisfazer tanto os partidários de uma política protecionista quanto os defensores do livre-cambismo.

Nícia Vilela Luz reconhece que o pensamento protecionista tinha muitos adeptos na década de 1840, mas destaca que, com "a finalidade precípua dos direitos aduaneiros de prover rendas ao Estado, foi decretada, em 1844, a tarifa Alves Branco, que tributou em 30\% a maioria dos produtos estrangeiros." 48 Sustenta sua tese com base em pesquisas da época. A comissão nomeada em 1843 para organizar uma nova pauta para as alfândegas do Império ${ }^{49}$ foi incumbida de aumentar para $50 \%$ e $60 \%$ as taxas sobre os artigos estrangeiros similares aos nacionais. Especificamente, as taxas sobre as manufaturas de algodão seriam de $60 \%$ para as mais grosseiras e $40 \%$ para as mais finas, nível considerado adequado para proteger a indústria nacional. Entretanto, as Tarifas Alves Branco firmaram em 30\% a taxa para manufaturas de algodão. A discrepância entre as instruções dadas e a tarifa tal como foi decretada decorreria das exigências do fisco.

Para tentar solucionar essa divergência historiográfica, é salutar recorrer novamente aos documentos históricos, por meio dos quais se tende a concluir que a tarifa foi uma opção majoritariamente fiscal.

\footnotetext{
${ }^{47}$ HOLANDA, Sérgio Buarque de. As tentativas de industrialização do Brasil. In: HOLANDA, Sérgio Buarque de (Org.). História Geral da Civilização Brasileira. $6^{a}$ ed. Rio de Janeiro: Bertrand Brasil, 2004. v. 4, p. 46.

${ }^{48}$ LUZ, Nícia Vilela. A luta pela industrialização do Brasil (1808 a 1930). $1^{\mathrm{a}}$ ed. São Paulo: Difusão Europeia do Livro, 1961. p. 18.

${ }^{49}$ BRASIL. Decreto n. 294, 17 de maio de 1843. Nomeando uma commissão, tendo por fim organisar a nova Pauta para as Alfandegas do Imperio. Lex: Colecção das Leis do Imperio do Brasil, Rio de Janeiro, vol. pt II, 1843, p. 69.
} 
A problemática das contas públicas fazia parte do cotidiano de diversos órgãos governamentais. Ano após ano, o Ministério da Fazenda expressava preocupação com o déficit orçamentário e o estágio da dívida estatal. Havia décadas que o Brasil apresentava balanços negativos, obrigando o país a recorrer a empréstimos externos, sobretudo com os ingleses. Já no início da década de 1840, o então Ministro Miguel Calmon du Pin e Almeida comentava que o déficit não era somente resultado de circunstâncias extraordinárias.

é forçoso fazer o sacrifício de já ir aumentando a receita do Estado, e não esperar pela época em que possamos elevar os direitos de importação, contraindo entretanto sucessivos, e por isso mesmo desvantajosos empréstimos, e o que mais lamentável é, diminuindo alguns dos impostos existentes, e há muito estabelecidos. Podemos contar, é verdade, com algum aumento na Renda Pública; mas receio que grande parte dele, senão todo, seja absorvido pelo inevitável aumento com que também podemos contar na Despesa Pública de um país novo. ${ }^{50}$

O discurso que se tornava recorrente no Ministério era da necessidade de aumentar as receitas. O Ministro Antônio Cavalcanti d'Albuquerque mostrou os números que comprovam o crescimento da dívida pública.

(...) o estado desta dívida no fim do exercício de 1844-1845 era de 6.960:794\$779, soma superior a do ano de 1843-1844 em 97:875\$890; $e$ sendo o acréscimo deste sobre o anterior 71:586\$010, faz ver o progressivo aumento deste sobre o anterior 71:587\$010, faz ver o progressivo aumento que de ano a ano vai tendo essa dívida. ${ }^{51}$

As isenções de importações de insumos, como a prevista no supracitado Regulamento das Alfândegas de 1832, foram objeto de reclamações de diversos Ministros da Fazenda por gerar renúncia de receita. Em 1848, Limpo de Abreu e Visconde de Abaeté queixavam-se de que "só as fábricas do Rio de Janeiro haviam deixado de recolher 74 contos de reis. Em 1851, Rodrigues Torres, Visconde de Itaboraí, repetia a queixa; a renúncia de receita superara 250 contos em $1850 " 52$. Em 1856, a renúncia ia além de 500 contos.

O Conselho de Estado, por diversas vezes, manifestou-se sobre o problema das contas públicas, sugerindo propostas para reverter o déficit público. Não faltaram pareceres e

${ }^{50}$ BRASIL. Ministério da Fazenda. Proposta e relatório do anno de 1840 apresentados a Assembléa Geral Legislativa na sessão ordinária de 1841. Rio de Janeiro: Typographia Nacional, 1841. p. 14.

${ }^{51}$ Id. Proposta e relatório do anno de 1846 apresentados a Assembléa Geral Legislativa na $4^{\mathrm{a}}$ sessão da $6^{\mathrm{a}}$ legislatura. Rio de Janeiro: Typographia Nacional, 1847. p. 23.

${ }^{52}$ VERSIANI, Flávio Rabelo. As Longas Raízes do Protecionismo: 1930 e as Relações entre Indústria e Governo. Revista EconomiA, Brasília, v. 13, n. 3b, dez. 2012, p. 875. 
relatórios sugerindo aumento de impostos e diminuição de gastos nas diversas esferas estatais, inclusive das províncias.

foi apresentada ao Conselho de Estado, o Parecer das Seções do Império, Fazenda e Estrangeiros do mesmo Conselho, relativo aos meios de aumentar a Receita Pública, e preencher o déficit atualmente conhecido: e este Parecer, depois de discutido, foi aprovado, não obstante as reflexões, que apareceram sobre um ou outro dentre os meios indicados pelas Seções para o sobredito fim. ${ }^{53}$

Nesse contexto pró-protecionismo e de pressão pelo aumento das receitas, são promulgadas as Tarifas Alves Branco. A partir da análise de documentos históricos, depara-se com um maior enfoque na importância fiscal da medida. Já no ano de 1840, Alves Branco mencionou que o fim dos tratados era excelente oportunidade para aumentar as tarifas e então equilibrar as despesas e receitas fiscais. ${ }^{54}$

A mesma opinião era repetida dois anos depois no Conselho de Estado, quando o projeto de aumento das tarifas alfandegárias começava a ganhar corpo, em função da proximidade do fim dos tratados comerciais.

O Senhor Vasconcelos ofereceu suas reflexões sobre a necessidade de algumas reformas nas Tesourarias Provinciais tendentes a diminuir muitas despesas. O Senhor Alves Branco respondendo assegurou, que o Projecto, que tinha de apresentar, compreendia idênticas idéias. ${ }^{55}$

Em agosto de 1845, Vasconcelos condenava o modo pelo qual Alves Branco havia fixado as tarifas de importação. O ministro teria escolhido as tarifas por motivos meramente fiscais. "Como podem desenvolver-se as fábricas, como hão de aparecer novos empreendedores à vista de semelhante método de proteção? Qual é a indústria que no seu começo não precise ser protegida?",56

\footnotetext{
${ }^{53}$ CONSELHO DE ESTADO PLENO. Atas do Conselho de Estado Pleno: Terceiro Conselho de Estado, 18421850. Disponível em: <http://www.senado.gov.br/publicacoes/anais/pdf/ACE/ATAS3Terceiro_Conselho_de_Estado_1842-1850.pdf $>$.p. 17.

${ }^{54}$ DEVEZA, Guilherme. Política tributária no período imperial. In: HOLANDA, Sérgio B. (Org.). História Geral da Civilização Brasileira. $5^{\text {a }}$ ed. Rio de Janeiro: Bertrand Brasil, 1995, v.2, tomo 4, p. 69-70.

${ }^{55}$ CONSELHO DE ESTADO PLENO. Atas do Conselho de Estado Pleno: Terceiro Conselho de Estado, 18421850. Disponível em: <http://www.senado.gov.br/publicacoes/anais/pdf/ACE/ATAS3Terceiro_Conselho_de_Estado_1842-1850.pdf >. Acesso em: 20 de setembro de 2010.p. 16.

${ }^{56}$ BRASIL. Senado Federal. Sessão de 11 de agosto de 1845, Anais do Senado. Brasília, v.3, p. 437-438.
} 
A maior ênfase no aspecto fiscal da Tarifa é encontrada em outros órgãos públicos. Em relatório do Ministério da Fazenda, embora seja ressalvado o objetivo de promover a industrialização do país, esse é considerado efeito indireto da medida.

tão avultada quota das rendas públicas merece maior atenção, tanto a respeito dos meios de sua melhor percepção, como da graduação das taxas sobre cada espécie de mercadorias, de sorte a produzir o duplo fim de maior renda, e de proteção ao trabalho nacional, que mereça a animação indireta, resultante das tarifas de importação. ${ }^{57}$

No mesmo relatório, a tarifa é vista positivamente em decorrência da elevação da receita estatal proporcionada, que aumenta ano após ano.

Era o espírito da Lei citada elevar os direitos da importação sobre as mercadorias estrangeiras tanto quanto fosse conveniente para dentro dos limites de 2 e 60\% saldar o déficit anual da Receita Pública; e foi neste sentido que se confeccionou a nova tarifa.

Mas teve-se igualmente em atenção proteger algumas indústrias já estabelecidas, ou em começo no Império, e tomando-se a taxa de 30\% como a geral sobre a importação estrangeira, foi modificada em algumas mercadorias, e especialmente nas de grande valor em pequenos volumes, $e$ naquelas que dão matéria-prima ao trabalho nacional; e elevada em outras, e principalmente sobre aquelas, que podem ser facilmente substituídas pelas de produção do Império.

Tomada em globo a nova tarifa, e em seus efeitos sobre o rendimento das Alfândegas, tem ela sido vantajosa, o que se reconhece da comparação do último ano anterior à sua execução, o de 1843-1844, em que foi de 12.266:344\$, com o de 1845-1846, primeiro em que a nova tarifa foi executada em todo o ano, e renderam 15.741:566\$. (...) Houve assim o aumento de $28,8 \%$ sobre o ano de $1843-1844 .{ }^{58}$

Os relatórios do Ministério de Negócios Estrangeiros também reconhecem o caráter protecionista das tarifas, mas novamente dão maior destaque ao aspecto fiscal da tarifa, como se observa na parte final do parágrafo seguinte.

O Brazil, porque nos tratados celebrados com quase todas as nações, tinha estabelecido geralmente os direitos modicos de quinze por cento para todos os generos de importação, e que em virtude desses tratados esteve por muitos annos com as mãos atadas, quer para augmentar sua receita elevando os direitos sobre alguns artigos que podessem comportar a elevação, quer para proteger algumas industrias nascentes, carregando mais, e dentro dos limites das necessidades fiscaes, productos de iguaes

\footnotetext{
${ }^{57}$ Id. Ministério da Fazenda. Proposta e relatório do anno de 1846 apresentados a Assembléa Geral Legislativa na $4^{\mathrm{a}}$ sessão da $6^{\mathrm{a}}$ legislatura. Rio de Janeiro: Typographia Nacional, 1847. p. 29.

${ }^{58}$ Ibidem.
} 
industrias estrangeiras, o Brazil, quando desligado de taes tratados, pôde attender a necessidade de augmentar suas rendas, elevou sua tarifa. ${ }^{59}$

Essa maior ênfase às pretensões fiscais fica bastante evidente em outra parte do supracitado relatório. Após ressaltar grandes acréscimos de despesas com revoltas provinciais, o Ministro José Joaquim Rodrigues Torres reconhece que as Tarifas Alves Branco vieram a atender essas e outras necessidades fiscais do Império, além de promover razoável proteção às manufaturas do Brasil. O emprego do adjetivo "razoável" mostra que o objetivo industrialista não foi completamente atingido.

A guerra do Rio da Prata, a guerra civil no Rio Grande do Sul e varias alterações nas instituições do paiz tinhão occasionado grandes accrescimos de despezas (...), e então, combinando as necessidades fiscais com a razoável protecção de algumas industrias do paiz, foi promulgada a nova tarifa de $1844 .^{60}$

Se as Tarifas Alves Branco focaram-se mais no objetivo fiscal e não proporcionaram a proteção aduaneira esperada, como explicar o surto de crescimento industrial de meados do século XIX? De fato, registrou-se a expansão de alguns setores, a exemplo do têxtil e metalúrgico. Todavia, esse crescimento foi reflexo mais da expansão econômica do Brasil na época, do que de uma política verdadeiramente protecionista. Para Sérgio Buarque, "animados pela esperança que a tarifa Alves Branco proporcionara, alguns pioneiros de espírito audaz provocaram uma inusitada atividade industrial nos meados do século." ${ }^{61} \mathrm{Um}$ desses pioneiros seria Irineu Evangelista de Souza, o Barão de Mauá.

\section{Conclusão}

A década de 1840 marcou um momento de ruptura na política econômica brasileira. Após décadas de submissão dos interesses nacionais à vontade das grandes potências — digase, Inglaterra -, sobretudo em função do conturbado período pós-independência, havia chegado a oportunidade, com o fim dos tratados com a Inglaterra e outras nações, de discutir uma nova política comercial e aduaneira que preservasse a autonomia alfandegária e lançasse

59 Id. Ministério dos Negócios Estrangeiros. Relatório do anno de 1849 apresentado a Assembléa Geral Legislativa na $1^{\text {a }}$ sessão da $8^{a}$ legislatura. Rio de Janeiro: Typographia Imperial e Constitucional de J. Villeneuve e Comp., 1850. p. S 34.

${ }^{60}$ Ibid. p. S 35.

${ }^{61}$ HOLANDA, Sérgio Buarque de. As tentativas de industrialização do Brasil. In: HOLANDA, Sérgio Buarque de (Org.). História Geral da Civilização Brasileira. 6a ed. Rio de Janeiro: Bertrand Brasil, 2004. v. 4, p. 46. 
as bases da indústria nacional. Como afirmava Paulino José Soares de Sousa, "presos por tratados, não nos podíamos mover." 62

Os debates cresceram nas mais diversas instituições governamentais e na elite imperial, surgindo grupos defensores do livre-cambismo e outros da industrialização brasileira. Dessas discussões, surgiram diversos projetos de tarifas protecionistas, sendo as Tarifas Alves Branco as mais famosas.

Os objetivos industrializantes, no entanto, não foram alcançados. Primeiramente, o Brasil não apresentava, naquele momento, as condições mínimas exigidas para um amplo processo de expansão manufatureira. País de estrutura produtiva e social arcaica, não dispunha de todos os meios de produção necessários para incentivar uma indústria competitiva o bastante a ponto de vencer a concorrência estrangeira. O país não possuía capital excedente e mercado consumidor, devido ao trabalho escravo, o que tornava mínimas as chances de se industrializar.

Parece igualmente claro, nos documentos históricos, que as tarifas de importação que compunham tal sistema protetor foram idealizadas mais para aumentar receitas fiscais que para promover a indústria. $\mathrm{O}$ ensaio de uma política alfandegária mais agressiva deveu-se, portanto, menos a tentativas conscientes de fomento industrial do que por necessidades puramente fiscais.

Em meados do século XIX, os impostos de importação respondiam por cerca de dois terços das receitas imperiais, e aos dirigentes brasileiros não interessava reduzir a renda de um Estado atolado em dívidas e déficits. Colocados nesse dilema entre promover a industrialização do País e atender, ao mesmo tempo, os interesses da lavoura e do físco, eles hesitaram em adotar uma política francamente protecionista, prorrogando a modernização e desenvolvimento manufatureiro do Brasil para o final do século XIX e início do XX.

\section{Referências Bibliográficas}

BRASIL. Alvará de $1^{\circ}$ de abril de 1808. Permitte o livre estabelecimento de fabricas e manufacturas no Estado do Brazil. Lex: Colecção das Leis do Brazil de 1808. Rio de Janeiro: Imprensa Nacional, 1891.

Decreto n. 376, 12 de agosto de 1844. Manda executar o Regulamento e Tarifa para as Alfandegas do Imperio. Lex: Colecção das Leis do Imperio do Brasil, Rio de Janeiro, tomo 7º, parte 2a , seção $26^{\mathrm{a}}, 1844$. Ministério da Fazenda. Proposta e relatório do anno de 1840 apresentados a Assembléa Geral Legislativa na sessão ordinária de 1841. Rio de Janeiro: Typographia Nacional, 1841. 30 p.

${ }^{62}$ CERVO, Amado Luiz; BUENO, Clodoaldo. História da política exterior do Brasil. 2. ed. Brasília: Editora Universidade de Brasília, 2002. p. 71. 
- Ministério da Fazenda. Proposta e relatório do anno de 1846 apresentados a Assembléa Geral Legislativa na $4^{\mathrm{a}}$ sessão da $6^{\mathrm{a}}$ legislatura. Rio de Janeiro: Typographia Nacional, 1847. 48 p.

- Ministério da Fazenda. Proposta e relatório do anno de 1849 apresentados a Assembléa Geral Legislativa na $1^{\text {a }}$ sessão da $8^{a}$ legislatura. Rio de Janeiro: Typographia Nacional, 1850. 38 p.

Ministério dos Negócios Estrangeiros. Relatório do anno de 1840 apresentado a Assembléa Geral

Legislativa na sessão ordinária de 1841. Rio de Janeiro: Typographia Nacional, 1841. 21 p.

- Ministério dos Negócios Estrangeiros. Relatório do anno de 1844 apresentado a Assembléa Geral Legislativa a 13 de janeiro de 1845, na $1^{\text {a }}$ sessão da $6^{\text {a }}$ legislatura. Rio de Janeiro: Typographia Nacional, 1845. $46 \mathrm{p}$.

Ministério dos Negócios Estrangeiros. Relatório do anno de 1846 apresentado a Assembléa Geral Legislativa na $4^{\text {a }}$ sessão da $6^{\text {a }}$ legislatura. Rio de Janeiro: Typographia Imperial e Constitucional de J. Villeneuve e Comp., 1847. 26 p.

Ministério dos Negócios Estrangeiros. Relatório do anno de 1847 apresentado a Assembléa Geral Legislativa na $1^{\circ}$ sessão da $7^{\mathrm{a}}$ legislatura. Rio de Janeiro: Typographia Nacional, 1848. 23 p.

Ministério dos Negócios Estrangeiros. Relatório do anno de 1849 apresentado a Assembléa Geral Legislativa na $1^{\text {a }}$ sessão da $8^{\text {a }}$ legislatura. Rio de Janeiro: Typographia Imperial e Constitucional de J. Villeneuve e Comp., 1850.17 p. Senado Federal. Sessão de 25 de abril de 1843. Anais do Senado. Brasília, v.4, 688 p. Senado Federal. Sessão de 27 de setembro de 1843. Anais do Senado. Brasília, v.8, 713 p. Senado Federal. Sessão de 28 de setembro de 1843. Anais do Senado. Brasília, v.8. 713 p. Senado Federal. Sessão de 29 de setembro de 1843. Anais do Senado. Brasília, v.8. 713 p. Senado Federal. Sessão de 11 de agosto de 1845. Anais do Senado. Brasília, v.3. 811 p.

CONSElHO DE ESTADO PLENO. Atas do Conselho de Estado Pleno: Terceiro Conselho de Estado, 1842 1850. Disponível em: <http://www.senado.gov.br/publicacoes/anais/pdf/ACE/ATAS3Terceiro_Conselho de Estado 1842-1850.pdf>. Acesso em: 20 de setembro de 2010.

ALMEIDA, Paulo Roberto. Formação da Diplomacia Econômica no Brasil: as relações econômicas internacionais no Império. Brasília: FUNAG, 2001.

CERVO, Amado Luiz; BUENO, Clodoaldo. História da política exterior do Brasil. 2. ed. Brasília: Editora Universidade de Brasília, 2002. 525 p.

CERVO, Amado. Política exterior e relações internacionais do Brasil: enfoque paradigmático. Revista Brasileira de Política Internacional, Brasília, vol. 46, n. 2, p. 5-25, 2003.

DE MELLO, João Manuel Cardoso. O capitalismo tardio: contribuição à revisão crítica da formação e do desenvolvimento da economia brasileira. $9^{a}$ ed. São Paulo: Brasiliense, 1998. 182 p.

DEVEZA, Guilherme. Política tributária no período imperial. In: HOLANDA, Sérgio B. (Org.). História Geral da Civilização Brasileira. $5^{\mathrm{a}}$ ed. Rio de Janeiro: Bertrand Brasil, 1995, v.2, tomo 4, p. 62-91.

FILHO, José Roberto Scandiucci. Hegemonia britânica e o debate entre protecionismo e livre-cambismo no Império brasileiro (1843-1866). Revista Múltipla, Brasília, vol. 9, n. 13, p. 61-90, dez. 2002.

HOLANDA, Sérgio Buarque de. As tentativas de industrialização do Brasil. In: HOLANDA, Sérgio Buarque de (Org.). História Geral da Civilização Brasileira. $6^{\mathrm{a}}$ ed. Rio de Janeiro: Bertrand Brasil, 2004. v. 4, p. 38-45.

LUZ, Nícia Vilela. A luta pela industrialização do Brasil (1808 a 1930). 1ª ed. São Paulo: Difusão Europeia do Livro, 1961. $216 \mathrm{p}$.

VERSIANI, Flávio Rabelo. As Longas Raízes do Protecionismo: 1930 e as Relações entre Indústria e Governo. Revista EconomiA, Brasília, v. 13, n. 3b, p. 867-895, dez, 2012. 